\title{
How to Avoid Discriminatory Words in Modern English
}

\author{
Naira Harutyunyan \\ Yerevan State University
}

$\mathrm{W}$ ord usage changes over time, words often come to mean more or less than they used to. Some words change in meaning, some become outmoded, some fall out of favor, and some words even become offensive instead of accepted and vice versa, they become accepted having been offensive once. Every day the demands to produce well-written and well-expressed communication grow in number and complexity. So the ability to write or to express oneself easily and effectively is valuable.

There is no doubt that a knowledge of accurate vocabulary is essential for the mastery of a language, we cannot use words unless we know how they should be put together, whether they are appropriate in this or that situation or not. For learners who are studying English in a non-English speaking setting it is very important to experience real communicative situations in which they learn to express their own views and attitudes, and in which they are taken seriously. Learning and mastering a foreign language is not just a matter of memorizing a different set of names for the things around us; it is also an educational experience, since language is closely linked with one's personality and culture. Thus, acquiring a new language one should gain further insights into the culture and personality of the natives.

The idea to write on words misused by EFL speakers occurred to me after an incident which happened to a teenager, who lived in London for seven years and learned English right among native speakers. At school, in Yerevan, he was once asked to fetch a piece of chalk. He got nervous and very offended to be "treated as a pet", as he later complained to his mother, a colleague of mine. In England and in other English-speaking countries they turn to their dog-pets to fetch a stick or something else, in this way trying to illustrate how clever their pets are. I clearly remember to have used this very word many times when asking for something, but it appears that there has been a change in usage over time and we, the teachers, should know about it.

The idea is that we must try to keep current; we must know the present meaning of words and how to use them in order not to be misunderstood. It is not easy for a nonnative speaker to master all the nuances of the words that are not commonly used or widespread or have recently undergone a slight change in meaning, let alone the fact that very often translated words may appear awkward to a native speaker.

Students often make mistakes when translating words having the component man, which has nothing to do with masculine gender but is derived from Latin manus, in the result of which the utterance becomes meaningless and, in most cases, silly.

In order to avoid being misunderstood we should know which words are too harsh, which are regional and redundant or they simply fog our intended meaning, and, why not, those which are offensive and should not be used at all. Every word should be chosen carefully, and the ones which are unnecessary or too vague should be eliminated.

According to Sandra E. Lamb, we should first of all avoid "sexist" language, i.e. gender-specific terms should be used as seldom as possible. "Avoid sexist language. Treat all 
readers equally. That means addressing men and women as equals in your communications" (Lamb 1998:308).

The main stress should be put on writing; whatever we write, be it a composition, a story, an essay or a letter, an invitation to a party, or maybe a resume, a request, a letter of condolence, or a response to a letter, we should know how to write it and try to use some effective means which will make the writing simple, clear and concise. The most important question here is "Who is my reader?" So it is essential to use the appropriate vocabulary for formal and informal messages.

The following points should be observed:

1. Avoid gender-specific terms by choosing the most inclusive and descriptive nongendered word.

The word chairman, for example, implies masculine gender, but the head of a meeting is not necessarily accepted to be a man. Instead of the word chairman we can use more inclusive words such as: the representative, the leader, the person responsible, the coordinator, the presiding officer, the head, etc.

Instead of manpower we can use workforce, employees, personnel, workers, staff, etc.

The idea is not to use man when we mean both men and women. We should be especially careful to use an inclusive term when we refer to all humans.

Thus, mankind can be replaced by people or humankind.

In manmade the prefix should be avoided using a more descriptive word, such as handmade or synthetic.

There are some "male-sounding" words containing man derived from the Latin manus, which means hand. Imagine how silly it is trying to translate words like manufacture, management, manipulate, manual, manuscript or manage, taking man for masculine gender, which, by the way, I have come across not once in my practice as a teacher. Replacing man in such cases is a silly error.

2. Avoid the he/she pronouns.

Usually we have no difficulty with the first-person or the second-person pronoun, but the third person pronoun can sometimes create problems for writers.

Although it has been common practice to address both sexes of readers as he, it is best to change the writing to avoid this problem. Several options can be observed in making changes:

- Use plural pronouns

For example, instead of saying

"If the student has questions, he should call the dean-office."

we can say

"If students have questions, they should call the dean-office."

- Reword to omit pronouns

We can change the same sentence to

"Students should call the dean-office with questions." (if any questions arise).

- Use second- or first- person pronouns 
"If you have questions, call the dean-office."

"I would call the dean-office if I had questions."

- Replace pronouns with the.

"The student should select his course at the beginning of the term."

"The student should select the course at the beginning of the term."

- Restructure the sentence to passive voice

"The course should be selected at the beginning of the term by the students."

Of course, passive voice should be used very sparingly and only if it emphasizes what we want to emphasize or provides needed variety in the sentence structure.

- Substitute one for pronouns

"The student has a choice to select the course; he should do it at the beginning of the term."

"The student has a choice to select the course; one should do it at the beginning of the term."

3. Avoid words that stereotype by race or nationality

Nationality and heritage word usage changes with time. The term preferred by the people we are describing should be used, and it should be used with sensitivity.

For example, we should not use black speaking about African Americans, the terms negro and colored are not preferred either. Native Americans are often called redskins or savages, which are offensive terms.

4. Avoid Age Discrimination.

Age terms that might offend should be avoided. Here is a chart taken from How to write it by Sandra E. Lamb (323) and Longman Dictionary of American English.

Before using this
adolescents
elderly
golden ager
middle-aged
oldster
senior citizens
teenagers
youngster
gaffer

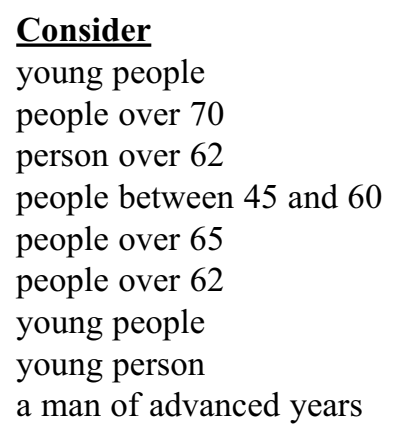

5. Avoid Stereotyping People with Disabilities.

Instead of

birth defect

crazy

crippled

\section{Use}

congenital disability specific medical term disabled 


$\begin{array}{ll}\text { deaf } & \text { individual who cannot hear } \\ \text { deaf and dumb } & \text { hearing and speech disabled }\end{array}$

In this table you can find some non gendered substitutions (selected from Longman, Oxford, Merriam-Webster's dictionaries) that are inclusive of both sexes and make logical sense:

$\begin{array}{ll}\text { Instead of } & \text { Use } \\ \text { Aircraftsman } & \text { aviator } \\ \text { Assemblyman } & \text { assembly person(worker), line person } \\ \text { bachelor's degree } & \text { undergraduate degree } \\ \text { barman } & \text { bartender, waiter } \\ \text { bagboy } & \text { assistant } \\ \text { busman } & \text { bus driver } \\ \text { cabin boy } & \text { crew member } \\ \text { cavemen } & \text { cave dwellers } \\ \text { chambermaid } & \text { housekeeper } \\ \text { choirgirl/boy } & \text { choir member } \\ \text { churchman } & \text { lay officer } \\ \text { clergymen } & \text { clergy, pastors } \\ \text { congressmen } & \text { members of congress, representatives } \\ \text { counterman } & \text { clerk } \\ \text { dairyman } & \text { dairy farmer (worker) } \\ \text { doorman } & \text { doorkeeper } \\ \text { fraternal twins } & \text { nonidentical twins } \\ \text { fatherland } & \text { homeland } \\ \text { fireman } & \text { firefighter } \\ \text { fisherman } & \text { fisher, angler } \\ \text { five-man committee } & \text { five-person committee } \\ \text { foreman } & \text { supervisor, leader, boss } \\ \text { freshmen } & \text { first-year students } \\ \text { g-man } & \text { government employee } \\ \text { gagman } & \text { writer of funny stories } \\ \text { man(girl) Friday } & \text { aide, helper, assistant } \\ \text { handyman } & \text { fixer, face-of-all-trades } \\ \text { headmaster } & \text { principal } \\ \text { insurance man } & \text { insurance agent } \\ \text { Johnny-come-lately } & \text { newcomer } \\ \text { Johnny-on the spot } & \text { prompter } \\ \text { King-size } & \text { huge, large } \\ \text { maiden name } & \text { birth (family) name } \\ \text { man among men } & \text { important person } \\ \text { man of the year } & \text { newsmaker of the year } \\ & \end{array}$




man on horseback
manhole
manhunt
manmade
motherland (country)
mother tongue
office boy
statesman
watchman

\author{
dictator, tyrant \\ utility hole \\ search \\ handmade \\ homeland, native country \\ native language \\ messenger \\ diplomat (or a specific title) \\ guard
}

\section{References:}

1. Friederike, K. (1984) Keep Talking. // Communicative Fluency Activities for Language Teaching. Cambridge: Cambridge University Press.

2. Ommagio, A. (1976). Real Communication: Speaking a Living Language. // Foreign Language Annals Vol.9 (2)

3. Lamb, S. E. (1998). How to Write It. // A Complete Guide to Everything You'll Ever Write. Berkeley, California, 94707: Ten Speed Press.

4. (2002) Longman Dictionary of American English. New ed. USA: Pearson Education.

5. (1988) Merriam Webster's Collegiate Thesaurus. Massachusetts:Incorporated Springfield.

6. (1998) Oxford Advanced Learner's Dictionary of Current English. Oxford.

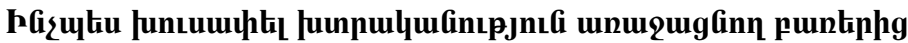 duưufiuluulhg ufiqteptinud}

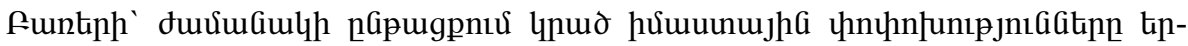

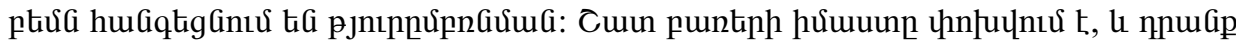

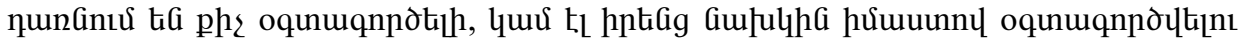

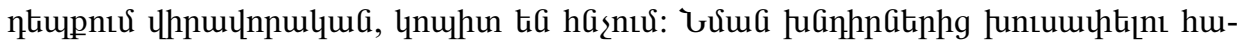

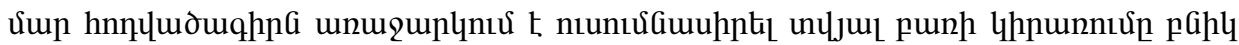

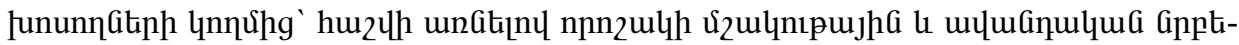

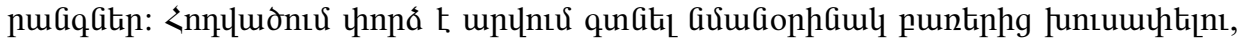

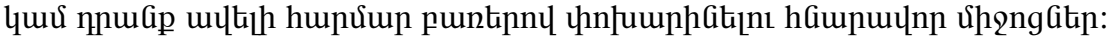

